\title{
Signos televisivos informativos de un prolongado estado de alarma: el caso uruguayo en los primeros ocho meses de la declaración de emergencia sanitaria
}

\author{
Fernando Andacht \\ Facultad de Información y Comunicación, Universidad de la República. \\ fernando.andacht@fic.edu.uy \\ ORCID: 0000-0003-3054-6090 \\ Gastón Amen \\ Facultad de Información y Comunicación, Universidad de la República. \\ gaston.amen@fic.edu.uy \\ ORCID: 0000-0001-5411-3965 \\ Fecha de finalización: 10 de diciembre de 2020 \\ Recibido: 24 de diciembre de 2020 \\ Aceptado: 31 de mayo de 2021. \\ DOI: https://doi.org/10.26422/aucom.2021.1001.and
}

\section{Resumen}

En este artículo se analizan los signos informativos de la televisión abierta uruguaya durante el período comprendido desde la declaración de la "emergencia sanitaria" del 13 de marzo de 2020 hasta noviembre de ese año. Se estudian tanto los frecuentes signos dedicados a anunciar el desastre inminente en el discurso mediático de los informativos televisivos, alternados esporádicamente con sucesos cubiertos bajo una modalidad narrativa épica -con foco en aspectos subjetivos e individuales-, como también la convergencia permanente de la voz gubernamental con la mediática. De este copioso discurso, se analizan las conferencias del Poder Ejecutivo en cadenas televisivas de facto (esto es, no planteadas oficialmente como tales, pero análogas en su funcionamiento y convergencia mediática), muy frecuentes en el período, con la teoría de los "acontecimientos mediáticos" (Dayan y Katz, 1995), aunque aquellas no encajen del todo con ese concepto. Así, se pudo constatar que, consideradas como una variante de las "ceremonias mediáticas transformativas" (Dayan y Katz, 1995), estas conferencias de prensa invocaron mitos centrales del Uruguay moderno con la finalidad de reforzar los valores establecidos, contribuir a la integración social y legitimar a las autoridades vigentes. También fue el modo de asimilar los nuevos e inciertos sucesos relacionados con la declarada pandemia de SARS-CoV-2 y sus posibles efectos locales dentro de los confines del "imaginario social" (Castoriadis, 2013) uruguayo. Igualmente, se señala cómo la manipulación discursiva en las conferencias, que tuvo como fundamento las directrices globales emitidas por la Organización Mundial de la Salud, 
intentó cumplir una función transformadora en dos etapas, tal cual lo ilustra la metáfora verbal "mover perillas" que usó el Gobierno: es posible avanzar o retroceder mediante esa operación. Concluimos que esta oscilación estaría en el núcleo del nuevo orden social que se pretende imponer mediante la persuasiva frase "la nueva normalidad", un contradictorio eslogan importado en el que confluyeron la voz política y la mediática.

Palabras clave: televisión, informativos televisivos, acontecimiento mediático, imaginario social uruguayo, conferencias gubernamentales, COVID-19.

\title{
Information signs on television during a prolonged state of alarm: the case of Uruguay in the first eight months of the pandemic's health emergency
}

\begin{abstract}
In this article, we look at the information signs that appeared on Uruguayan public television between March 13, 2020 - when a health emergency was declared - and November of the same year. We analyze the recurring signs pointing to an imminent disaster across the media discourse of television news programs. These were mixed with coverage of events in an epic narrative mode, with a focus on subjective and individual details. We also underline the persistent convergence of government and media voices. Within this broad discursive context, we consider the Executive Branch's de facto television addresses, which were very frequent during this period. These were not official addresses, but they played a similar role, in terms of their function and the media convergence they enabled. Our analysis uses the theory of "media events" (Dayan and Katz, 1995), even though our topic does not fall neatly within the bounds of this concept. We found these addresses or press conferences - considered as variants of "transformative media ceremonies" (Dayan and Katz, 1995) - were able to invoke some of the central myths about modern Uruguay with the aim of reinforcing established values, contributing to social integration, and legitimizing the current government. They were also a way to assimilate the uncertainty of the SARS-CoV-2 pandemic - and of its potential local effects - within the confines of a Uruguayan "social imaginary" (Castoriadis, 2013). These conferences followed the global directives of the World Health Organization. And their discursive manipulation had a transformative goal, across two distinct stages, as illustrated by the government's "turning knobs" metaphor, in which the same operation or gesture can move things forward or backwards. We conclude this oscillation is at the heart of the new social order or "new normal," a contradictory and imported slogan that brought together government and media voices.
\end{abstract}

Keywords: television, television news, media events, Uruguayan social imaginary, government conferences, COVID-19.

\section{Signos televisivos informativos de um prolongado estado de alarme: o caso uruguaio nos primeiros oito meses após a declaração de emergência sanitária \\ Resumo}

No artigo analisamos os signos informativos da televisão aberta uruguaia durante o período que vai da declaração da "emergência sanitária" do 13 de março de 2020 a novembro desse mesmo ano. Consideram-se os frequentes signos dedicados ao anúncio do desastre iminente no discurso midiático dos telejornais, alternados esporadicamente com acontecimentos cobertos sob a modalidade narrativa épica - com foco em aspectos subjetivos e individuais -, bem como a convergência permanente da voz governamental com a voz da mídia. 


\title{
Austral Comunicación \\ Volumen 10, número 1 (junio de 2021): 87-118 ISSN (I) 2313-9129. ISSN (E) 2313-9137
}

\begin{abstract}
A partir desse copioso discurso, analisam-se as conferências do Poder Executivo em redes de televisão de fato (ou seja, não oficialmente apresentadas como tal, mas análogas em seu funcionamento e convergência midiática), muito frequentes no período, com a teoria dos "acontecimentos midiáticos" (Dayan e Katz, 1995), embora as conferências não se encaixem bem com esse conceito. Assim, constatou-se que, consideradas como uma variante das "cerimônias midiáticas transformadoras" (Dayan e Katz, 1995), essas conferências de imprensa invocaram mitos centrais do Uruguai moderno a fim de reforçar os valores estabelecidos, contribuir para a integração social e legitimar as autoridades atuais. Foi também a forma de assimilar os eventos novos e incertos relacionados à declarada pandemia SARS-CoV-2 e seus possíveis efeitos locais dentro dos limites do "imaginário social" uruguaio (Castoriadis, 2013).
\end{abstract}

Palavras chave: televisão, telejornais, acontecimento midiático, imaginário social uruguaio, conferências de imprensa do governo, COVID-19.

\section{Introducción: el día que la televisión abierta e informativa volvió a la vida}

En un ensayo recientemente publicado, Andacht (2020b) compara la recuperada popularidad de la televisión abierta en Uruguay a partir del 13 de marzo de 2020, fecha en la que el Gobierno declaró la "emergencia sanitaria", con una criatura sobrenatural, pues "como un cadáver reanimado, el zombi, la televisión abierta recuperó la vitalidad y salió a comer cerebros con inmensa voracidad y entusiasmo creciente" (Andacht 2020b, párr. 2). De ese modo, hizo referencia a la masiva y ubicua presencia de la voz gubernamental durante todo el día en los tres canales privados, más el público de la ciudad de Montevideo (TV Ciudad) y la red televisiva de alcance nacional (TNU), siete días a la semana y muchas horas por día. La duración habitual de la edición central y vespertina pasó de una hora a dos horas y media, y durante los tres primeros meses fue habitual ver una suerte de transmisión en cadena de facto, ya que pese a no recibir el nombre de cadena de prensa, ofició como tal. Alrededor de las 20 horas, era una imagen familiar la transmisión de la conferencia de prensa desde la Torre Libertad, sede del Poder Ejecutivo uruguayo, a veces con el presidente, otras con el secretario de Presidencia acompañado por diversos ministros, según el tópico pandémico del día.

Nuestro interés en este artículo es analizar un prolongado estado de alarma vehiculizado por la puesta en escena televisual e informativa, que de pronto, crisis sanitaria mediante, adquirió una relevancia extraordinaria que, desde aquel día inaugural en las postrimerías del verano austral, no parece disminuir. Esto es especialmente llamativo a nivel local -no global, tal vez- porque las cifras de infectados por el nuevo coronavirus y las de muertes que se supone ha ocasionado no parecen justificar en absoluto tal despliegue de signos relacionados con la pandemia, especialmente si se comparan tales datos con las muertes causadas en el país por otras enfermedades, por ejemplo, las 
Fernando Andacht, Gastón Amen

Signos televisivos informativos de un prolongado estado de alarma: el caso uruguayo en los primeros ocho meses de la declaración de emergencia sanitaria

cardiovasculares o el cáncer. ${ }^{1}$ A partir de la constatación de este hecho, se revisitará la conceptualización elaborada por Dayan y Katz (1995) en torno a los "acontecimientos mediáticos". ¿En qué se diferencia la situación informativa en la televisión uruguaya, en el marco de los primeros ocho meses de la declarada emergencia sanitaria, de casos clásicos sobre los cuales estos investigadores han trabajado? ¿Pueden usarse sus nociones teóricas para analizar un suceso global y prolongado, aun si es de aplicación local, como la pandemia de la COVID-19? Estas son las preguntas centrales que procuramos responder en este artículo.

\section{Explicitación de aspectos teórico-metodológicos}

El abordaje teórico-metodológico de este trabajo es socio-semiótico. Se fundamenta en la semiótica triádica de Peirce y en la teoría del imaginario social de Castoriadis (2013); incorpora asimismo elementos conceptuales del clásico estudio comunicacional de Dayan y Katz (1995) sobre las ceremonias televisuales. La estrategia metodológica adoptada consiste en una "investigación documental" (Valles, 1997, pp. 109-139) centrada en documentos audiovisuales de tipo secundario, como lo son los informativos de la televisión abierta uruguaya emitidos durante el período estudiado, esto es, entre el 13 de marzo de 2020 -día en que se declaró la emergencia sanitaria en Uruguayy mediados del mes de noviembre de ese mismo año. El trabajo de campo consistió en la observación de numerosas ediciones noticiosas de los canales de la televisión abierta uruguaya a lo largo de todo el período. Esta observación se basó en un "diseño emergente" (Valles, 1997, pp. 76-77), lo que nos permitió reconocer la centralidad de las conferencias gubernamentales en los informativos televisivos, sobre todo en los primeros meses. Esto tuvo como consecuencia que en el diseño de la investigación se incluyera la elaboración de una muestra de aquellas. Para su confección, se practicó una "selección estratégica de casos" siguiendo pautas de "muestreo teórico" (Valles, 1997, p. 92), con el fin de buscar específicamente aspectos que se pudieran vincular con la literatura especializada acerca del imaginario social uruguayo. El corpus así elaborado fue analizado a partir de la perspectiva teórico-metodológica señalada, lo que implicó poner en práctica una metodología de tipo cualitativo, la cual posee un sustento u objeto empírico y procede mediante observaciones que Peirce $(1931-1958,1.239)^{2}$ denomina “cenoscópicas", es decir que no se basan en la utilización de aparatos especiales ni en contabilizar ocurrencias, como lo hace una encuesta probabilística con muestreo aleatorio, pero no por eso es menos rigurosa o empírica desde el punto de vista

\footnotetext{
En este sentido, en una entrevista radial realizada recientemente a la epidemióloga Lucía Alonso, indicó que "el riesgo de morir de Covid en Uruguay hoy es de 1 por 100 mil habitantes y de, por ejemplo, enfermedad cardiovascular, un infarto, es de 200 por 100 mil, o de cáncer, por encima de 200 por 100 mil" (No Toquen Nada, 2020).

2 Citamos la obra Collected Papers of C. S. Peirce (1931-1958) del modo convencional: "x.xxx" remite al número de volumen y párrafo de esta publicación.
} 


\section{Austral@municación \\ Volumen 10, número 1 (junio de 2021): 87-118 ISSN (I) 2313-9129. ISSN (E) 2313-9137}

científico. Sus resultados pueden y deben someterse al escrutinio de la comunidad de investigadores, de modo análogo a otros abordajes científicos de naturaleza cualitativa.

\section{Crónica de una muerte postergada}

En el campo de los estudios de la comunicación, ha sido un tema de investigación recurrente el de las mutaciones que los nuevos medios generan en la ecología mediática que los antecede. Así, con el desarrollo de internet y de la digitalización, se generó un espacio de investigación y debate en torno al impacto que esto tendría sobre los medios masivos tradicionales, anunciando distintos investigadores importantes transformaciones e incluso el fin de estos últimos. Un trabajo pionero en este sentido fue el de Toffler (1982), quien se refirió a un proceso de desmasificación de los medios de comunicación: "Los medios de comunicación de masas se hallan sometidos a intenso ataque. Nuevos y desmasificados medios de comunicación están proliferando, desafiando - $y$, a veces, incluso reemplazando- a los medios de comunicación de masas" (p. 196). Proceso que en su perspectiva sería consustancial al pasaje desde sociedades industriales de la segunda ola a sociedades informacionales de la tercera ola.

En lo que respecta específicamente a la televisión, que fue "considerada el gran depredador mediático de la era del broadcasting (en sus épocas doradas la televisión amenazó de muerte al cine, la radio y la prensa)" (Carlón y Scolari, 2009, p. 9), con el desarrollo de la digitalización e internet, y en la misma línea anticipada por Toffler (1982), se anunció la cercanía de su fin, lo que en algunos casos aludía al fin del aparato televisor; en otros, al de la programación; a veces, al abandono de una práctica social hogareña; y en otras, al negocio de la televisión (Carlón, 2009, p. 163).

Entre quienes primero anunciaron la muerte de la televisión hay dos trabajos elocuentes. Uno es el de Gilder (1992), en el que el autor se basa en los desarrollos en la tecnología informática y de la fibra óptica y anuncia la muerte de la televisión y la telefonía tradicionales, además de la emergencia de un nuevo paradigma comunicacional basado en los enlaces establecidos entre computadoras presentes en los distintos hogares y oficinas. Otro es el de Pérez de Silva (2000), en el que, refiriéndose a la nueva producción audiovisual en la era de internet, señala: "Muere la forma actual de hacer televisión, muere la forma actual de ver televisión, y por último, muere también el aparato que hasta ahora conocíamos como televisor" (pp. 18-19).

En el contexto regional, quien desarrolló tempranamente esta línea de investigación fue Piscitelli $(1995 ; 1998)$, que se refirió a la defunción de la televisión clásica y su sustitución por la tele-computación: "Computadoras personales adaptadas para el procesamiento de video y conectadas a través de la fibra óptica a todas las telecomputadoras del mundo" (Piscitelli 1995: 22). Lo que lo llevó, asimismo, a desarrollar su 
Fernando Andacht, Gastón Amen

Signos televisivos informativos de un prolongado estado de alarma: el caso uruguayo en los primeros ocho meses de la declaración de emergencia sanitaria

concepto de post-televisión, que resalta el pasaje de la televisión clásica, analógica, a la digital e interactiva (Piscitelli, 1995; 1998).

En todo caso, estos trabajos que han puesto el acento en las transformaciones experimentadas en la ecología mediática, y específicamente en el debilitamiento o transformación de los medios masivos tradicionales, llevarían a predecir consecuencias análogas en el campo de la información televisiva. Tal evolución conduciría de modo probable o previsible a un debilitamiento del noticiero televisivo como producto audiovisual masivo, inserto en una programación y bajo una lógica de broadcasting. Pero, en lugar de esto, en Uruguay distintos trabajos han evidenciado, desde los momentos en los que se comenzaban a realizar aquellos pronósticos del ocaso de los medios masivos hasta la actualidad, la continuada relevancia del informativo televisivo en esta sociedad (Álvarez, 1988; Amen, 2019; Pereira, 2014).

A esta vigencia duradera se le agrega, además, que bajo el contexto de excepcionalidad que se suscitó a partir de la declaración de la emergencia sanitaria por parte del Gobierno uruguayo, el noticiero televisivo se ha revigorizado y aumentó notoriamente su público, como también su duración en un 150 por ciento.

Así, con respecto a lo primero, si bien desde hace décadas el informativo televisivo es uno de los programas con mayores niveles de audiencia en Uruguay (Álvarez, 1988; Amen, 2019; Radakovich, 2009), en el contexto de los primeros meses de declarada la "emergencia sanitaria", que es el período que aquí analizamos, el número de sus espectadores aumentó de modo considerable. Precisamente, cuando aún no se cumplía la semana de la declaración de emergencia sanitaria, en un portal de noticias local se indicaba que

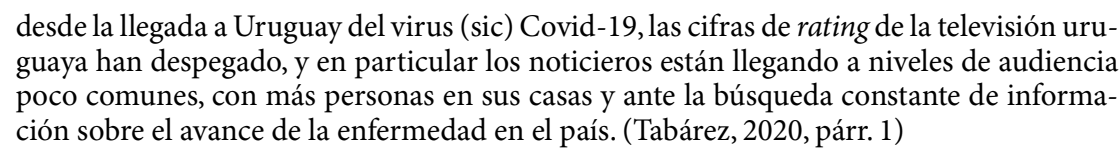
guaya han despegado, y en particular los noticieros están llegando a niveles de audiencia poco comunes, con más personas en sus casas y ante la búsqueda constante de información sobre el avance de la enfermedad en el país. (Tabárez, 2020, párr. 1)

Esto se ratificó un mes después en un medio de prensa (Medina, 2020), así como también a través de los datos continuos de seguimiento de rating de Kantar Ibope Media.

En todo caso, este incremento en la audiencia televisiva era esperable, si tomamos en cuenta que, como se señalaba en el portal de noticias, la población había sido exhortada a permanecer en su hogar. Tal recomendación hizo que este producto audiovisual contara con un público potencial mucho mayor y que las noticias vinculadas con el tema refirieran a asuntos que afectaban directa e inmediatamente a la población. Se puede hablar en este caso, de modo casi literal, de un "público cautivo" (Andacht, 2020a). A este fenómeno se le sumó, como ya comentamos, que durante el transcurso de los informativos se volvió una práctica habitual la transmisión en vivo de conferen- 


\section{Austral Comunicación \\ Volumen 10, número 1 (junio de 2021): 87-118 ISSN (I) 2313-9129. ISSN (E) 2313-9137}

cias de prensa del Gobierno, las primeras semanas en forma diaria, y luego en forma frecuente. Arrastrados o influenciados por la antes rara ocurrencia del mensaje del Gobierno emitido "en cadena", es decir, por la totalidad de los canales abiertos uruguayos, espectadores que habían sido aleccionados sobre el grave peligro que corrían sus vidas y que ya tenían la tendencia a prestar particular atención al discurso excepcional de la cadena televisiva, se encontraban predispuestos a cambiar su hábito de consumo televisual a causa de esa doble anomalía: la del dispositivo televisivo y la sanitaria. Por tanto, no sorprende ese incremento en la audiencia, lo cual, a pesar de su carácter muy predecible, casi diríamos inevitable, pasó a ser mencionado con gran orgullo como una conquista en los propios noticieros, en una especie de inusual ejercicio de autocelebración comercial explícita y reiterada.

Además de alcanzar un nivel de público inédito, los informativos de los canales privados hicieron un rediseño radical de su extensión horaria como parte de esa actitud celebratoria. La ubicación de la edición central de estos programas reviste un carácter ritual, casi religioso, en cuanto a su inamovilidad. Subrayado, el informativo de Canal 10, fue el primero en hacer modificaciones: adelantó su comienzo media hora a partir del lunes 16 de marzo, empezando a las 18:30 y extendiéndose muchas veces hasta pasadas las 21 horas. Telemundo, el informativo de Canal 12, a partir del martes 17 de marzo comenzó a emitirse en el horario comprendido entre las 18.30 y las 21.30 horas, agregando así más de una hora a su duración habitual. En tanto, en Telenoche, el informativo de Canal 4, si bien no se efectuaron modificaciones en su horario, en algunas jornadas las transmisiones se extendieron más de lo habitual por la llegada de noticias relacionadas con la pandemia, que sus productores consideraron lo ameritaban. Los tópicos podían ser conferencias de prensa del Gobierno u otras novedades. Un caso extremo de este repertorio pandémico tuvo lugar el 10 de abril, cuando con motivo de la extensa e intensa cobertura del desembarco de los pasajeros del crucero Greg Mortimer para que regresaran a sus respectivos países en un muy publicitado corredor humanitario, Telenoche se emitió desde las 18:20 hasta las 22:30 horas, alcanzando las insólitas cuatro horas continuas de emisión. Incluso, no parece exagerado hablar de la "saga" de ese crucero de bandera australiana durante más de dos meses -del 6 de abril al 22 de mayo- si nos atenemos al protagonismo narrativo que los pasajeros y tripulantes de esa nave tuvieron en todos los informativos uruguayos.

A lo anterior habría que añadirle los distintos tipos de programas informativos y de actualidad que fueron surgiendo de modo constante a medida que se extendía la emergencia sanitaria. Todos ellos se centraban exclusivamente en la temática de la declarada pandemia.

Este mismo tipo de fenómenos en Argentina generó la inquietud de “¿cuánta información somos capaces de soportar?". Pues si bien "consumir información forma 
Fernando Andacht, Gastón Amen

Signos televisivos informativos de un prolongado estado de alarma: el caso uruguayo en los primeros ocho meses de la declaración de emergencia sanitaria

parte de nuestra cultura y colabora en mantener el equilibrio en las sociedades: fomenta conversaciones, permite conocer sobre otras realidades, tiene un rol pedagógico y promueve ciertas gratificaciones", no podemos desconocer que "estas cualidades cambian cuando la agenda mediática está hegemonizada por un solo tema, y más aún, si ese tópico se vincula con riesgos de salud pública" (Focás, 2020). Es que esta estrategia televisiva entraña el no menor riesgo de generar pánico en la población, así como sensaciones de malestar y elevada vulnerabilidad personal, todo lo cual va en desmedro de la razonabilidad necesaria para enfrentar la situación excepcional que comenzó a vivirse a partir de la declaración de la emergencia sanitaria. A esto deberíamos agregarle un factor fundamental: no solo se trata de un menú informativo monotemático, sino que se lo aborda desde una única perspectiva, lo que incide considerablemente en el efecto de sentido o interpretación planeada desde todos estos medios de comunicación masiva. ${ }^{3}$

Cuando el lógico Peirce, en 1903, revisó su "máxima pragmática" de 1878 -el método lógico que propuso para calcular el significado de un concepto o signo general-, sostuvo el valor de ese principio analítico para "alcanzar un grado relativamente alto de claridad de pensamiento" (Peirce, 1931-1958, 5.1). Lo que Peirce agregó como justificación de su sostenida convicción en el pragmaticismo es relevante para comprender el impacto negativo de esa saturación informativa caracterizada por su condición de discurso unánime, lo cual empobrece de modo considerable el aporte plural y abierto de la ciencia para entender el fenómeno del coronavirus SARS-CoV-2:

\begin{abstract}
debemos recordar que el único bien supremo al cual los hechos prácticos a los que [la máxima pragmática] dirige la atención pueden ser útiles es para incrementar el desarrollo de la razonabilidad concreta; de tal modo que, el significado del concepto no radica en ninguna reacción individual en absoluto, sino en el modo según el cual esas reacciones contribuyen a ese desarrollo. (Peirce, 1931-1958, 5.1)
\end{abstract}

El discurso noticioso ocupa la atención y alarma de los espectadores con la crónica minuciosa de esa multitud de "reacciones individuales" que construyen los informativos a través de la cobertura del crucero Greg Mortimer. Nada se explica ni se analiza en relación con las implicancias generales y valiosas, desde el punto de vista médico y científico, que posee la infección a bordo de esa nave para el mejor conocimiento de la enfermedad COVID-19. Por el contrario, se trató la noticia según el modo épico: un destaque del valor extraordinario de los médicos que subieron a bordo, el 6 de abril de 2020, antes de que se le permitiese anclar en el puerto de Montevideo, y la exhibición de pintorescas muestras de agradecimiento de algunos pasajeros evacuados, como la de besar el suelo del puerto, al estilo papal. En un registro tonal heroico, esta extensa

Este es el resultado de la observación hecha por los autores de los cinco canales de televisión abierta de Montevideo: tres privados, uno estatal y otro municipal durante los meses que abarcó la investigación. 


\section{Austral Comunicación \\ Volumen 10, número 1 (junio de 2021): 87-118 ISSN (I) 2313-9129. ISSN (E) 2313-9137}

y detallada narrativa es la contrapartida de las sucesivas amenazas y alarmas del muy anunciado y temido "pico", es decir, la explosión de casos de infección, los cuales nunca llegaron a registrarse en el período estudiado. En lugar del deseable proceso lógico evolutivo de lo que Peirce $(1931-1958,5.4)$ describe como "el crecimiento de la razonabilidad", lo que tiende a generar este tipo de cobertura es un nivel alto de angustia, de alarma constante, lo cual termina por afectar la protección natural del ser humano, es decir, su sistema inmunitario. Tal como lo afirman Gómez González y Escobar (2006), "durante la exposición del organismo al estrés ocurre hipofuncionamiento del sistema inmune, con lo que el organismo queda expuesto a la acción de los agentes infecciosos del ambiente, es más susceptible a padecer enfermedades e incluso puede sucumbir" (p. 31).

Nos enfrentamos entonces a una situación atípica: la de un noticiero televisivo con una audiencia mucho mayor que la habitual, que de por sí es alta, ${ }^{4} \mathrm{y}$ con una extraordinaria extensión en relación con su duración normal, lo cual se da, además, en el marco de una programación alterada para darle una cabida amplísima a todo lo relativo a la pandemia y bajo una modalidad de broadcasting. Entonces, pareciera ser que nuevamente, por la llegada de una crisis sanitaria de gran magnitud, no solo se ha postergado de modo espectacular la siempre anunciada muerte de la televisión, sino que esta recuperó su plena salud, es decir, su misión inaugural: el cometido de alimentar en vivo, ya sea real o ilusoriamente, el apetito del público por la realidad informativa.

En línea con lo anterior, recordemos la advertencia efectuada por Scolari (2009), quien pese a señalar que el modelo de medio centralizado, unidireccional y masivo de la televisión está gravemente herido -y, con él, el viejo reino del broadcasting- agregó que igualmente, ante ciertos eventos, se volverían "a congregar las masas de manera simultánea delante de las pantallas (de todas las pantallas, las macro y las micro, las viejas y las nuevas)" (p. 203). Incluso, más allá de los cambios que haya podido experimentar la televisión en las últimas décadas, no es de descartar que "preserve espacios de broadcasting (bajo forma de transmisión en vivo y en directo) dentro de su dispositivo" (Scolari, 2009, p. 203). Justamente, el directo televisivo, que ha sido caracterizado por Carlón (2009, p. 170) como la gran novedad y el rasgo distintivo que instauró este medio y que lo distinguió del cine, considerado como el núcleo de lo mediático televisivo, resistiría al menos en dos sentidos:

\footnotetext{
Para contextualizar esto, vale señalar que investigaciones realizadas en distintos períodos en Uruguay (Álvarez, 1988 Amen, 2019; Radakovich, 2009) han destacado que los informativos centrales de la televisión abierta se encuentran entre los programas más vistos de la televisión uruguaya, dándose una clara continuidad al respecto. A su vez, esta centralidad de los informativos se vio acentuada a partir de la declaración de la emergencia sanitaria, período durante el cual alcanzaron audiencias semejantes a las logradas por la televisión local en las retransmisiones televisivas de fenómenos puntuales de gran relevancia, como por ejemplo los debates entre candidatos presidenciales en la última elección nacional (Tabárez, 2020).
} 
Fernando Andacht, Gastón Amen

Signos televisivos informativos de un prolongado estado de alarma: el caso uruguayo en los primeros ocho meses de la declaración de emergencia sanitaria

\begin{abstract}
Por un lado, va a seguir generando discursos masivos (e incluso globales) a través de transmisiones de acontecimientos y eventos, ya sea de la historia política, del deporte, del espectáculo o de aquello que en un futuro la sociedad considere de valor. Por otro, se mantendrá intacto como lenguaje, obligando al sujeto espectador, no importa en qué pantalla lo vea $[\ldots]$ a movilizar los mismos saberes técnicos, discursivos y sobre el mundo que obligó a poner en juego al primer sujeto espectador televisivo para ser comprendido: podremos creer, entonces, que no estamos viendo televisión, pero nos vamos a equivocar; en términos discursivos estaremos asistiendo, una y otra vez, a su extraordinaria novedad. (Carlón, 2009, pp. 171-172)
\end{abstract}

De lo citado se rescata la idea de la necesidad para el público de "movilizar los mismos saberes técnicos, discursivos y sobre el mundo" que tuvo que emplear para volverse un competente espectador televisual. Hoy, más de una década después, ese medio, aprovechando su transmisión en directo y en contacto con las fuentes del poder tanto político como médico-científico oficial, logra abrir un nuevo capítulo de su reinado gracias al nivel de miedo o alarma constante que ocupa gran parte de su horario ampliado para difundir su narrativa sobre la pandemia en Uruguay.

\title{
Contenidos de los noticieros televisivos en épocas de emergencia sanitaria
}

Los cambios que ocurrieron en los noticieros televisivos uruguayos no solamente implicaron un incremento en su duración y en la cantidad de público espectador, sino también notorias modificaciones en sus contenidos y en la puesta en escena. De esta manera, a diferencia de los noticieros uruguayos de la segunda mitad de los 80 , que se caracterizaron por la preeminencia de la temática política en un contexto de reciente salida de la dictadura (Álvarez, 1988), también se distinguieron de los informativos que pusieron en un sitio central a la crónica policial con posterioridad a la crisis de 2002 y por casi dos lustros (Amen, 2019; Natalevich y Silvera, 2011; Perroni, 2009). A partir de mediados de marzo de 2020, la temática de la COVID-19 no solo se volvió central, sino casi excluyente. En este sentido, incluso la tradicional segunda temática principal del género, la deportiva -o, más ajustadamente, la dedicada al fútbol-, en los primeros meses de emergencia sanitaria que aquí analizamos se redujo y se reconfiguró, incluyendo en un ámbito inesperado los impactos de la COVID-19. La consecuencia más importante, naturalmente, fue la suspensión del deporte en general y del fútbol en particular a raíz de la pandemia declarada por la Organización Mundial de la Salud (OMS). De esa manera, la temática de la COVID-19 se volvió hegemónica en los informativos televisivos no solo por ocupar como noticia en sí misma un lugar central, sino también por invadir otras secciones, que fueron reconfiguradas teniendo en cuenta cómo la emergencia sanitaria y la declarada pandemia afectaban distintas esferas de la vida social, económica, cultural y política. 


\section{Austral Comunicación \\ Volumen 10, número 1 (junio de 2021): 87-118 ISSN (I) 2313-9129. ISSN (E) 2313-9137}

A lo anterior se le agregaron cuatro elementos que garantizaron la preeminencia absoluta de esta temática: 1) el que algunos periodistas, por encontrarse en el grupo de riesgo de contagio, comenzaron a participar del noticiero desde sus casas; 2) que los periodistas e invitados al estudio, siguiendo las recomendaciones sanitarias, comenzaron a guardar distancia física entre ellos; 3 ) el hecho notorio de que los movileros comenzaron a usar en sus notas tapabocas o máscaras protectoras faciales; y 4) la emisión inusual de frecuentes conferencias gubernamentales en torno a la temática, que por su relevancia trataremos en el siguiente apartado. De este modo, la múltiple e inagotable representación de la COVID-19 y del virus que la causa logró hacerse inevitable en todos los noticieros de Uruguay. ${ }^{5}$

Esta omnipresencia, como era de esperar, también comportó modificaciones en la opinión pública, lo cual fue tematizado en los propios noticieros, aunque curiosamente se lo presentó como si fuera una información del todo sorprendente en vez de ser algo por completo previsible, en función de esa irradiación sistemática y masiva. Así, según una encuesta de Cifra (Para el $44 \%$ de los uruguayos..., 2020) realizada entre el 17 y el 18 de abril de 2020 a nivel nacional, el principal problema del país para los uruguayos era la salud y la COVID-19, alcanzando el 44 por ciento; en segundo lugar se ubicó la desocupación y el cierre de empresas, con el 20 por ciento; y en tercer lugar, la situación económica del país, con el 17 por ciento. La inseguridad, en tanto, alcanzó apenas el 5 por ciento, lo cual contrasta fuertemente con las encuestas de opinión previas a la emergencia sanitaria, en las cuales, de modo regular, la seguridad se ubicaba en primer lugar. En tal sentido, en noviembre de 2019, en una encuesta realizada también por Cifra, el porcentaje de uruguayos que consideraba que la seguridad era el principal problema alcanzaba el 53 por ciento, en tanto que la salud no era considerada como una problemática (Para el $44 \%$ de los uruguayos..., 2020).

\section{Conferencias gubernamentales y "acontecimientos mediáticos"}

El cambio de contenidos en los informativos televisivos también incluyó, como se mencionó anteriormente, la emisión de las casi cotidianas conferencias gubernamentales en directo, que giraban en torno a las novedades del avance de la enfermedad en el país, así como a las medidas que se iban disponiendo para enfrentarlo. Creemos que estas conferencias pueden ser abordadas fructíferamente teniendo en cuenta algunos aportes conceptuales de Dayan y Katz (1995) sobre los "acontecimientos mediáticos", aunque, como veremos enseguida, no se las puede considerar como un caso que se ajuste completamente a esta teorización. En este sentido, una de las características principales de los "acontecimientos mediáticos", tal cual son definidos por estos autores, es la interrupción

Para un análisis de la iconografía atemorizante producida por los informativos uruguayos, ver Andacht (2020a). 
de la rutina: "Interfieren el flujo normal de las emisiones y el de nuestras vidas" (p. 14). Así, en cuanto al primer aspecto, la interrupción de las rutinas de emisión es de carácter monopolista, dado que "todos los canales cambian su programación regular por el gran acontecimiento" (p. 14). En lo referente al segundo aspecto, implica una modificación en la vida cotidiana de los espectadores, quienes ven alteradas sus rutinas por el evento mediático.

Se pueden reconocer estas dos dimensiones en los primeros días en los que se llevaron adelante las conferencias del Gobierno en el contexto de la recién instaurada emergencia sanitaria, cuando la comunicación solemne y adusta del equipo gubernamental a cargo del presidente, que materializaba la entrada imperativa de la voz política y autorizada en las casas, alteró las emisiones normales de los noticieros al ser emitida en directo por todos los canales. ${ }^{6} \mathrm{Al}$ mismo tiempo, esa inusitada irrupción modificó también las rutinas de los televidentes, quienes, exhortados a permanecer en sus hogares, esperaban expectantes las últimas novedades gubernamentales en torno al avance de la declarada pandemia en su versión local. De todos modos, creemos que no se ajusta del todo a la conceptualización desarrollada por Dayan y Katz (1995), sino que más bien parece tratarse de una especie de cadena televisiva de facto bajo un régimen espectacular, dado que rápidamente, con el transcurso de los días, estas conferencias se integraron con fluidez a la estructura informativa diaria y/o semanal. Debido a esto, teóricamente no podrían ser consideradas como esa clase de interferencia, de abrupto quiebre o instalación de un momento fuera del tiempo, como sí lo fue el aterrizaje del primer hombre en la luna o la boda de Lady Di, para poner ejemplos tratados justamente por Dayan y Katz (1995). Hay que agregar que, aunque atenuadas, estas cadenas televisivas de facto persisten al momento de escribir este trabajo. Si nos detenemos en la representación del tono melodramático de la pandemia, en este género habitualmente menos enfático, es posible afirmar que la tensión cuidadosamente producida a lo largo de toda la emisión central del informativo culmina o llega al clímax mediante la conexión en vivo y en directo con Torre Ejecutiva, sede del Poder Ejecutivo uruguayo. ${ }^{7}$

Otras características de los "acontecimientos mediáticos" que se suman a la interrupción de la rutina y a su emisión en directo son, por un lado, su carácter remoto, esto es que se organizan fuera de los medios, tanto en el sentido que se realizan fuera

\footnotetext{
La transmisión en directo es otra de las características distintivas de los “acontecimientos mediáticos”, según Dayan y Katz (1995).

Solo un estudio de recepción nos permitiría afirmar con mayor certeza si, tras varios meses y habiendo asistido a decenas de esas conferencias del Gobierno sobre el estado de la pandemia y sus efectos en los diversos ámbitos de la sociedad, ese acontecimiento continúa produciendo un elevado impacto emocional o si, por el contrario, ya ha sido asimilado a una suerte de columna casi fija o estable, no del todo diferente a la que se dedica a reportar los crímenes del día. A favor de tal conjetura tenemos el reporte cotidiano desde las inmediaciones del edificio emblemático del poder gubernamental sobre el número de test positivos, de personas cursando la enfermedad COVID-19, de pacientes en tratamiento intensivo, de recuperados y de muertos.
} 


\section{Austral Comunicación \\ Volumen 10, número 1 (junio de 2021): 87-118 ISSN (I) 2313-9129. ISSN (E) 2313-9137}

de estudios -en este caso, en la sala de prensa de la Torre Ejecutiva- como también que su origen o producción no se da en los propios medios. En tal sentido, la iniciativa apoyada de modo unánime y notorio por todos los canales privados de televisión corrió por cuenta del Gobierno. Por otro lado, estos acontecimientos poseen un carácter planificado. No es infrecuente que haya un clima de suspenso, de gran expectativa, el cual se genera por las sucesivas entradas infructuosas del periodista destacado en la sala de conferencias de prensa de la sede del Poder Ejecutivo, quien anuncia que aún hay que esperar algunos minutos más para que por fin lleguen al lugar esas figuras que se volvieron tan conocidas por el público como los propios rostros de los profesionales de la televisión. Por ende, pronto se vuelve evidente que esas ocasiones comunicacionales siempre están cuidadosamente planeadas, de ahí que se las anuncie por anticipado, y a modo de justificación, el presidente, con un tono que mezclaba modestia y la fatiga de quien está continuamente inmerso en una tarea titánica, ofrecía invariablemente la explicación de que recién lograba salir de una reunión con asesores científicos, por ejemplo. Estas palabras no solo servían de justificación para su tardanza, sino que lo investían de un aura heroica, de máxima dedicación a proteger a la ciudadanía, que se extendía por contigüidad a los funcionarios de gobierno acompañantes. El haber conseguido esa clase de potente sinergia entre el deseo del poder político de ser representado a diario como un paladín del bien público y la lente amplificadora de los medios masivos, como lo son los canales de televisión, es el sueño de todo Gobierno, a saber: conseguir que la mediatización se ponga literalmente al servicio, a la paciente espera de la enunciación hecha desde el poder, para darle la más amplia y unánime difusión, para volver irresistiblemente verosímil su discurso pandémico.

Desde una actitud neodurkheimiana, Dayan y Katz $(1995$, p. 8) ven estos acontecimientos como generadores de solidaridad mecánica - un sentido de pertenencia, similitud, igualdad, familiaridad-, como un llamado a la unidad e integración social, el cual ha estado presente en estas conferencias, en las que se ha convocado a la unión de los uruguayos para combatir al denominado "enemigo invisible". Esta actitud puede compararse con la noción de "comunidad imaginada" (Anderson, 2016); pese a no cruzarse en las calles -y mucho menos en momentos de confinamiento exhortado o voluntario-, la población uruguaya sabe que forma parte de una misma nación, precisamente gracias al funcionamiento de varios artefactos comunicacionales (Anderson, 2016), como lo son, en este caso, los informativos televisivos, elementos tradicionales de cohesión imaginaria nacional. En definitiva, qué momento más propicio para la producción de esa solidaridad mecánica que el conocimiento que poseen tantas personas de estar viendo lo mismo que tantos otros con igual atención en ese mismo momento. A diferencia de cantar al unísono el himno nacional o de leer el periódico del día -los dos ejemplos que propone Anderson (2016)-, el ver y oír cada día -casi 
Fernando Andacht, Gastón Amen

Signos televisivos informativos de un prolongado estado de alarma: el caso uruguayo en los primeros ocho meses de la declaración de emergencia sanitaria

a la misma hora por todos los canales televisivos- la lectura de la lista de contagiados y/o muertos, que con frecuencia va acompañada de lo que se supone que es el discurso reasegurador del actor político, produce un momento de gran carga afectiva.

Esta invocación a la unidad nacional se puede ejemplificar concretamente mediante tres intervenciones del secretario de la Presidencia, Álvaro Delgado. Primero, la de la conferencia de prensa del 14 de marzo, un día después de la declaración de la emergencia sanitaria, esa que oficia como una declaración de guerra al virus. En esa ocasión, Delgado señaló: "Esto es un tema nacional que está por encima de cualquier tipo de diferencia o disputa. Acá es el Uruguay entero peleando contra una amenaza". La segunda vez fue la conferencia del día posterior, cuando el funcionario indicó: "Acá todos tenemos conciencia que al coronavirus le ganamos entre todos y todos tenemos que estar comprometidos en ese proceso". Se trata de una invocación épica, que no es exagerado comparar con lo que podríamos imaginar fue el histórico llamado del prócer J. G. Artigas a emprender el éxodo del pueblo oriental, en 1811, aunque en este caso no se tratase de un llamado al desplazamiento hacia lo incierto, sino, por el contrario, de una exhortación al encierro sedentario en una suerte de petición de un simulacro: no salgan, hagan de cuenta que todos, sin excepción, cada uno de nosotros, los habitantes del país, constituye un peligro potencial para el prójimo. Finalmente, destacamos de Delgado su papel en la conferencia del 17 de marzo, en la que reafirmó el carácter agonista del desafío, así como el compromiso nacional al respecto: "Al coronavirus le vamos a ganar entre todos". Esa apelación a la victoria, en tierra uruguaya, tiene un aire inconfundible de gesta épico-deportiva, lo que fue descrito como "la maracanización del mundo" de la vida (Andacht, 1996).

Aunque tal vez la expresión más relevante en este sentido fue la del presidente Luis Lacalle Pou, en la conferencia del jueves 19 de marzo, cuando luego de saludar, al comenzar el evento, dijo:

En este momento, miles de uruguayos se convocaron para aplaudir y agradecerle la tarea y el esfuerzo al personal de la salud. Queremos adherir desde acá lo que está pasando afuera de este edificio y en gran parte del país, por el trabajo que miles de hombres y de mujeres están haciendo a lo largo y ancho de todo nuestro territorio y merecen nuestro agradecimiento y nuestro reconocimiento. Agradecerles también a los voluntarios.

De ese modo apacible, pero vehemente, quien se ha encargado desde el inicio de la crisis de encarnar al héroe individual -en gestación o construcción permanente- ese día saluda y homenajea al héroe colectivo, el que ya ha sido consagrado por el pueblo confinado. Se le permite esa módica y modesta salida, esa expresión de admiración unánime y sonora de lo heroico sanitario.

De esta manera, a través de su adhesión al ritual de los aplausos en agradecimiento al personal de la salud y a los voluntarios, que bien pudo haber surgido por imitación 


\section{Austral Comunicación \\ Volumen 10, número 1 (junio de 2021): 87-118 ISSN (I) 2313-9129. ISSN (E) 2313-9137}

a otros países en los que esta práctica ya era habitual en aquel momento, el presidente alentó el sentimiento de explícita y eufórica unidad nacional, comunitaria en plena crisis. Y, como se dijo antes, llega también hasta él algo de ese derrame emocional positivo: es un elemento fundamental en ese momento tan rotundamente disfórico, de encierro voluntario no amenazado por castigo jurídico en caso de su transgresión, algo para festejar, disponer de algo positivo en el presente. Fuimos testigos de un casi imposible kairos -el tiempo fuerte redimido del olvido- en medio del temible chronos -la pura rutina del pasaje muerto del tiempo-, inaugurado por la crisis sanitaria impuesta. ${ }^{8}$ Algo particularmente ominoso de esa imposición tan fuerte, que sí constituye un acontecimiento memorable, primero y único en la historia del aún joven siglo XXI, quedaría atenuado por la alegría a la que exhorta el presidente para unirse mediante el símbolo de la aprobación enfática, festiva. Lo decretado por el Gobierno es el cierre de clases, clubes de deporte, espectáculos de toda índole, comercios -excepto farmacias y alimentación- y hotelería: se ha decretado así un efecto similar al efecto patógeno del tétano a gran parte de la economía y de los servicios que son utilizados para aprender, distenderse o mantenerse con buena salud. También serviría ese discurso de la alegría para amenizar al menos un poco los sucesivos e intensos mensajes para no acercarse al sistema hospitalario o de atención mutual privada, salvo en caso de emergencia y/o de ser atacados por el enemigo invisible y casi nunca nombrado en los medios, a saber: el nuevo coronavirus SARS-CoV-2.

Aunque no hay una prohibición legal de salir, se anula o cancela casi todo lugar al cual se podría acudir, ya sea para comprar -salvo la comida, obviamente- o para divertirse sanamente. Ese golpe o dura restricción a la libertad de movimiento es compensada por los nuevos ritos o ceremonias en los que sí pueden participar los confinados: ovacionar al personal de la salud, pero hacerlo desde la protección y máxima seguridad de su confinamiento.

Por otra parte, la búsqueda de la unidad nacional, más allá de las diferencias, también se expresó en esta última conferencia en el soslayamiento o postergación de elementos polémicos. De esta manera, ante la consulta de un periodista de si había posibilidades de aplazar el aumento de tarifas de los servicios públicos anunciado unos días antes, Lacalle Pou respondió:

No. No y me entenderán que no quiera abundar en la situación que llevó a la readecuación tarifaria. No es momento de hacerlo. Nosotros estamos mirando hoy y para delante. Pero podríamos hablar de esa situación. Ustedes la conocen de memoria.

8 Para una discusión iluminadora sobre esta oposición clásica de la civilización griega, ver Kermode (1967). 
Fernando Andacht, Gastón Amen

Signos televisivos informativos de un prolongado estado de alarma: el caso uruguayo en los primeros ocho meses de la declaración de emergencia sanitaria

Evitó así entrar en la polémica que ocurrió durante la transición de gobierno, cuando el presidente electo le reclamara -con resultados infructuosos- a Tabaré Vázquez, presidente todavía en funciones, que aumentara las tarifas antes de cederle el Gobierno.

Asimismo, el carácter de mancomunión que estos eventos evocan incluye a los periodistas, con quienes el presidente Lacalle Pou se ha mostrado afable y sonriente, y a quienes les ha agradecido en varias ocasiones las preguntas que le realizaban. Esto, sumado a la práctica tanto suya como del secretario de presidencia, Álvaro Delgado, de catalogar de "muy buenas preguntas" ciertas consultas de los periodistas, pueden llevar a pensar en un uso performativo del habla y en un manejo de refuerzos positivos en el vínculo gubernamental con ellos. Se fomenta de esta manera ciertos tipos de comportamientos y se desestimulan otros. Aunque mostrarse gentil o amable con quien los interroga públicamente tiene un aspecto protocolar e incluso ritual, en esta crisis, esa actitud explicita y pone de manifiesto la importancia suprema de mantener en funciones la sinergia o, podría decirse, el total y envidiable acoplamiento -para cualquier poder político- con la voz mediática. Tener a todos los medios de comunicación de su lado es un requisito clave a la hora de mantener ese férreo control -suavizado por la frase "solo exhortamos"-, pero revelado en toda su magnitud por el decreto de cierre de casi todo lo que se puede hacer en la esfera pública.

En este sentido, el jueves 19 de marzo, en el cierre de la conferencia de prensa de ese día, Lacalle Pou les dijo a los periodistas: "Darles las buenas noches y agradecerles la seriedad con que han informado estos días. Es muy importante la tarea de ustedes para llevar tranquilidad y calma a los uruguayos, así que agradecerles el esfuerzo". Además de ser parte de la constante búsqueda de fomentar un esfuerzo mancomunado -lo que sin duda contribuye a construir la representación pacificada del actor estatal-, tal enunciado puede interpretarse también como un intento de amortiguar, de aminorar la innegable violencia del frenazo completo e irreversible de la vida cotidiana como la conocíamos. Se trata de un reconocimiento gubernamental a los periodistas mediante elementos discursivos de tipo performativo, que apuntan a que estos cumplan eficaz y regularmente esa función tranquilizante.

En la convocatoria a la unidad realizada en las conferencias gubernamentales, los símbolos patrios también se hicieron presentes para aportar una dosis adicional de legitimidad nacionalista. En este sentido, en su "medio" o "trasfondo escénico" (Goffman, 1997), se ha podido observar el escudo nacional en su nueva versión, la cual surgió del cambio de identidad visual del Poder Ejecutivo, y fue presentada menos de dos semanas antes de la conferencia en la que se declaró la emergencia sanitaria.

Finalmente, con respecto a la unidad nacional promovida por el Gobierno en las conferencias de prensa, es notoria la presencia siempre conjunta de diversas autoridades del Ejecutivo, siendo el ejemplo más emblemático el del 13 de marzo, cuando 


\section{Austral Comunicación \\ Volumen 10, número 1 (junio de 2021): 87-118 ISSN (I) 2313-9129. ISSN (E) 2313-9137}

se decretó la emergencia sanitaria. Esa alocución formal fue liderada por el presidente Lacalle Pou y participaron, sentados a su lado, el secretario de presidencia, Álvaro Delgado, y el ministro de salud, Daniel Salinas. En tanto, varios ministros y la presidenta del Congreso de Intendentes acompañaron de pie, formados atrás de esa primera línea gubernamental. Presencia conjunta de protección paternalista de la nación amenazada.

\section{De conferencias gubernamentales y mitos nacionales}

En las conferencias de prensa se pudieron detectar algunos mitos que caracterizan al Uruguay moderno, como lo son los mitos de la garra charrúa, la excepcionalidad uruguaya y la medianía o mesocracia.

Con respecto al primero de ellos, tanto el ministro de Salud Pública Salinas como el presidente Lacalle Pou lo reivindicaron. Salinas dijo en la conferencia de prensa del 14 de marzo: "Frente a la adversidad los uruguayos nos agrandamos, y en este momento no va a ser diferente". Mientras que Lacalle Pou señaló en la conferencia del 16 de marzo: "Yo quiero como presidente de la República reconocer y agradecer una vez más a ese uruguayo que en momentos difíciles sale adelante y saca lo mejor de sí". El 19 de marzo apeló nuevamente de modo implícito a la legendaria, inexistente e implausible, pero siempre invocada, garra charrúa, ${ }^{9}$ ese impulso que nos conduciría a la victoria en los momentos adversos, ya sea en el deporte o en la vida cotidiana, cuando señaló: "Agradecerles también a los voluntarios, porque, como decíamos el otro día cuando hablábamos con ustedes, estas situaciones sacan lo mejor de cada uruguayo, y se han convocado para tratar de dar una mano en todo lo que hace a lo necesario en estos días". Es decir, todas invocaciones a ese "plus de concentración, sobreesfuerzo y competitividad épica en los momentos más difíciles o disputados" (Bayce, 2005, p. 187) en la que consiste, precisamente, la mítica garra charrúa.

En lo que respecta al mito de la excepcionalidad uruguaya, también fue reivindicado por el ministro Salinas y por el presidente. En el caso del ministro de Salud Pública, dijo en la conferencia del sábado 14 de marzo: "Tenemos que reaccionar como una comunidad inteligente y como siempre nos ha distinguido [...] por eso en esta etapa estamos tomando medidas que otros países tomaron muchos días después", a lo que añadió:

Lo que hemos analizado profundamente en este ministerio es estar por delante, no llevarnos por delante, sino estar adelantados a las medidas de la OMS y a la experiencia adquirida en el sentido de tomar medidas más drásticas al inicio para tener mejores resultados al final, que es lo que se ha demostrado científicamente que está dando resultado.

\footnotetext{
Para una discusión reciente sobre lo irreal de haber utilizado desde inicios del siglo XX esa noción como una descripción elogiosa de la selección nacional de fútbol, ver Borges (2019).
} 
Fernando Andacht, Gastón Amen

Signos televisivos informativos de un prolongado estado de alarma: el caso uruguayo en los primeros ocho meses de la declaración de emergencia sanitaria

Esto es destacado también por Lacalle Pou en la conferencia del jueves 19 de marzo: "Cuando comparamos con lo sugerido por la Organización Mundial de la Salud y otros países, estamos adelantando muchas de las medidas, las estamos tomando antes de la fase pertinente". Se trata, en todos estos casos, de reivindicaciones de que el país estaría a la vanguardia, con un basamento aparentemente científico en lo que respecta a la gestión de la declarada pandemia. Esto también incluye combinaciones con otros mitos, como lo es el del Uruguay ilustrado, el "mito de un país de ciudadanos cultos" (Rial, 1986, p. 24), en el citado llamado de Salinas a reaccionar como una "comunidad inteligente y como siempre nos ha distinguido".

Finalmente, en lo referido a la alusión a la ideología nacional de la medianía o mesocracia (Real de Azúa, 1964), el ejemplo más elocuente ocurrió durante la conferencia del 16 de marzo, en la que el presidente señaló:

Aprovechamos una vez más a agradecerles a los trabajadores públicos y privados que es-
tán haciendo un gran esfuerzo en estos días. Nosotros somos los que salimos en la prensa,
pero en estos momentos y durante muchas horas [hay] gente trabajando denodadamente
para tratar de hacer pasar esta situación lo mejor posible. Agradecerle a ese Uruguay que
emerge en estos momentos, que es el Uruguay solidario.

La referencia implícita, pero inequívoca, a la medianía como tesitura colectiva idealizada en este caso se expresaría en ese presunto no querer sobresalir de los integrantes del Ejecutivo en el esfuerzo colectivamente desplegado. Decimos "presunto" pues, más allá de lo discursivo, la presencia cotidiana en los medios masivos a través de las propias conferencias parecería remitir a lo contrario. En todo caso, lo que existe indudablemente aquí es un intento de construcción de una figura heroica colectiva, un Obdulio Varela ${ }^{10}$ del esfuerzo compartido por apoyar el bienestar de la nación. Así, entonces, este destaque del trabajo denodado de esa multitud anónima de funcionarios reivindicaría una hazaña grupal e intentaría minimizar su posición protagónica, en línea con esa "religión estatal uruguaya" que constituye la "mesocracia" (Andacht, 1992) y que rehúye de modo llamativo toda ocasión de jactancia. Surge así un curioso fenómeno: el de la "jactancia negativa" (Andacht, 1996, p. 57), es decir, el acto de jactarse de modo ostensible de no jactarse sobre algún logro o conquista, como lo es aquí la victoria frente a la pandemia de COVID-19.

Esta alusión a esos mitos relevantes del "imaginario social" (Castoriadis, 2013) uruguayo puede entenderse mejor si se tiene en cuenta que los "acontecimientos mediáticos" -en este caso, las conferencias gubernamentales entendidas como variantes heterodoxas de estos- apelan siempre a resaltar "algún valor central o algún aspecto de la memoria colectiva" (Dayan y Katz, 1995, p. 8). Se trata de un mecanismo discursivo

${ }_{10}$ Obdulio Jacinto Varela (1917-1996) fue el capitán del equipo uruguayo de fútbol que venció al seleccionado brasileño en el partido final de la Copa del Mundo, en el Estadio de Maracaná, en Río de Janeiro, el 16 de julio de 1950. 


\section{Austral Comunicación \\ Volumen 10, número 1 (junio de 2021): 87-118 ISSN (I) 2313-9129. ISSN (E) 2313-9137}

mediante el cual, en forma ceremonial, el poder político-estatal contribuye a la integración social apelando a mitos consolidados en el imaginario social de referencia.

\section{¿“Chamanización” de las conferencias gubernamentales?}

Los "acontecimientos mediáticos", de acuerdo con la conceptualización de Dayan y Katz (1995), son "ceremonias mediáticas" que se caracterizan por reforzar los valores establecidos y buscar legitimar a las autoridades vigentes, al tiempo que algunos de ellos también comportan una dimensión "transformadora". A estos últimos, estos autores los denominan "chamánicos", pues "comportan un cambio perceptible tanto en el ámbito simbólico como en el de lo real” (p. 121).

$\mathrm{Al}$ igual que en la actividad chamánica descrita por los antropólogos, en este tipo de acontecimientos mediáticos transformadores se opera una manipulación simbólica en la que es crucial el consenso grupal para su eficacia. Por otra parte, también los mitos cumplen en ellos la función de hacer inteligible y persuasiva la situación experimentada para intervenir en ella, pues se busca, a través de una ceremonia mediática ritual en la que se interpretan ciertos mitos, conseguir una transformación de la realidad:

La retransmisión ceremonial de una propuesta de cambio puede, en ciertas condiciones, llevar realmente a ese cambio. El proceso recuerda el fenómeno que los antropólogos denominan eficiencia simbólica ${ }^{11}$ en sus análisis de curaciones y transformaciones chamánicas. (Dayan y Katz, 1995, pp. 121-122)

En algunos casos, las "ceremonias mediáticas" responden a acontecimientos externos, ya sean cíclicos y esperados o únicos e inesperados. Las conferencias gubernamentales, precisamente, fueron una respuesta a un acontecimiento de carácter mundial, único e inesperado, como lo ha sido la declarada pandemia del SARS-CoV-2. Estas conferencias, por tanto, pueden ser entendidas como "primeros intentos de establecer los significados de los acontecimientos y de institucionalizarlos en la memoria colectiva" (Dayan y Katz, 1995, p. 124).

El desarrollo de la declarada pandemia y los primeros casos en territorio uruguayo exigieron atención e interpretación, y las conferencias aquí abordadas han intentado dar una respuesta gubernamental en este sentido. Pues "sin una ceremonia, el acceso a un acontecimiento todavía destacado dependería sólo de las noticias de los medios de comunicación" (Dayan y Katz, 1995, p. 124). En términos semióticos, se diría que, a través de esa práctica, se avanza desde el impacto ciego y bruto de la semiosis indicial, del hecho que ocurre y que en sí mismo es "sordo" (Peirce, 1931-1958, 7.628), es decir, incomprensible o ininteligible -hacia el plano simbólico- de lo interpretable de

${ }^{11}$ Énfasis en el original. 
Fernando Andacht, Gastón Amen

Signos televisivos informativos de un prolongado estado de alarma: el caso uruguayo en los primeros ocho meses de la declaración de emergencia sanitaria

un modo que es en buena medida regular, previsible y, por ende, compartible por una comunidad sígnica. ${ }^{12}$

Estas conferencias, como se ha visto, han implicado el recurso a algunos de los principales mitos presentes en el "imaginario social" del Uruguay moderno, como modo de asimilar los nuevos e inciertos sucesos vinculados a la declarada epidemia mundial de SARS-CoV-2 y a sus posibles efectos locales en los confines del "imaginario social" uruguayo. Por tanto, es posible entender y analizar las conferencias gubernamentales emitidas en cadena de facto en todos los noticieros, en el marco de la emergencia sanitaria, como una serie de "ceremonias que hablan al acontecimiento para urgirlo a una apacible transición deseada (o impuesta)" (Dayan y Katz, 1995, p. 122).

Considerado como una serie de "ceremonias", este discurso ha apuntado a una función transformadora, pues en las conferencias del Gobierno se ha tratado de ilustrar o escenificar soluciones posibles y deseables, a nivel local, a una declarada crisis sanitaria mundial. Esta forma de respuesta involucró elementos biopolíticos, pues las medidas gubernamentales frente a la crisis sanitaria conllevan una "biorregulación por el Estado", expresan cierta "biopolítica de la población" (Foucault, 1978), que se debe entender como un "problema a la vez científico y político, como problema biológico y como problema de poder" (Foucault, 2000, p. 222).

A las primeras medidas de emergencia frente a la declarada pandemia, a la suspensión de muchas actividades normales de la vida cotidiana, se le agregó posteriormente una meta intermedia según la cual orientarse: el período que fue denominado "la nueva normalidad". La frase posee un antecedente en el ámbito de la economía y las finanzas, en el que se lo utilizó para describir las nuevas condiciones financieras luego de la crisis de 2008 y las secuelas de la Gran Recesión comenzada ese año. ${ }^{13}$ En el contexto actual, la frase ha sido empleada por el director de la OMS, Tedros Adhanom, y también por diversos Gobiernos para aludir a un período de retorno paulatino y por etapas, poscuarentena, a diversas actividades sociales y económicas. Incluso se sugiere que habría una migración irreversible a un mundo que ya no tendría muchas de las características que componen y definen lo que entendemos por (vida/ mundo) "normal". De modo superficial, pero relevante, se trata de un período que estaría caracterizado por la aplicación de estrictos protocolos sanitarios en la vida social, que incluyen el uso de tapabocas y el mantenimiento de cierta distancia física entre las personas, entre otras medidas presentadas como de defensa contra el virus SARS-CoV-2.

12 Peirce (1931-1958, 7.628) describe así la ciega irrupción del hecho: "La fuerza del juicio perceptual se aproxima a la pura falta de razonabilidad del percepto, sólo en esta medida, en que sí asevera representar el percepto, mientras que la perfección de la sordera del percepto consiste en que no asevera nada".

13 Algunas fuentes atribuyen el uso de la frase en inglés the new normal a títulos de libros referidos al mundo pos-11 de setiembre de 2001. Por ejemplo, Assessing the New Normal: Liberty and Security for the post-September 11 USA (2003) (Origin of 'the new normal'..., 2014). 


\section{Austral Comunicación \\ Volumen 10, número 1 (junio de 2021): 87-118 ISSN (I) 2313-9129. ISSN (E) 2313-9137}

\section{La "nueva normalidad" en Uruguay y las “perillas" del Gobierno}

El análisis del eslogan "La nueva normalidad", lanzado a la opinión pública el 17 de abril, es relevante. La frase posee un significado paradójico, pero la constante reiteración le confirió plausibilidad; oficia como eje ideológico de la propuesta política que apoyó con unánime energía la voz mediática. Constituye una anomalía hablar de una nueva normalidad, pues, por definición, la normalidad no puede serlo. Tampoco sería plausible referirse a una vieja normalidad. Lo definible como "normal" tiende a la invisibilidad, pues produce una especie de anestesia local: es un fenómeno tan familiar que ya no se lo percibe. Lo descrito como "normal" se ausenta de la percepción por estar siempre ahí, su familiaridad no causa alarma, aunque su naturaleza "no es estática ni pacífica" (Canguilhem, 1991, p. 239). Una nueva realidad -como un golpe de Estadoes perceptible, incluso dolorosa: todo se altera de modo súbito y radical, el mundo de la vida se transforma irreversiblemente y no es posible ignorarlo. La normalidad se vive como una firme plataforma, transcurre en un tiempo crónico (Kermode, 1967, p. 48) que se limita a transcurrir sin llamar la atención ni producir sospechas ni temores.

Todo es bizarro y desfamiliarizador en la operación política y mediática de la "nueva normalidad", salvo la tentativa evidente de que no parezca algo bizarro. Para ese fin, justamente, se apela y convoca a la "nueva normalidad" de forma cotidiana y ubicua a través de los medios, como si solo se tratase de una razonable idea salvadora y amortiguadora del malestar actual. Su presencia constante no hace que esa curiosa conjunción del adjetivo euforizante y del sustantivo apacible y por completo ajeno a esa clase de adjetivación sea menos implausible y aberrante. La meta del enunciado es clara: la sociedad pasaría a adoptarlo y a aceptarlo como el lema o rótulo tranquilizante para minimizar todo lo siniestro e intranquilizador que ocurre a cada momento, en buena medida como resultado de las estrategias desplegadas para combatir la enfermedad. Lo inocultable es que ese bautismo oficial de la crisis sanitaria, a un mes de su comienzo en el país, no consigue ocultar su condición de fenómeno "extraño" o "siniestro", según lo describió Freud (1919), mediante el atributo sustantivado das unheimliche, que podría traducirse como "lo desfamiliarizado" o "el extrañamiento" (de algo familiar y conocido) que irrumpe en una pesadilla o en la cotidianeidad de esta tercera década del siglo XXI.

En este contexto, bajo la narración hegemónica de la OMS orientada hacia la meta imaginaria de una vida que transcurra dentro de los parámetros de la "nueva normalidad", es que se inscribe lo acontecido en Uruguay a partir del 13 de marzo de 2020. Experiencia local, entonces, de un suceso de conmoción global, en el que el Gobierno ha recurrido al uso de las conferencias de prensa como "ceremonias mediáticas transformativas", en un sentido ampliado de esa noción, en las que no solo se utilizaron los mitos vernáculos para asimilar simbólicamente la situación excepcional de alarma 
Fernando Andacht, Gastón Amen

Signos televisivos informativos de un prolongado estado de alarma: el caso uruguayo en los primeros ocho meses de la declaración de emergencia sanitaria

mundial, alentar la cohesión social y buscar legitimar al Gobierno, sino también para impulsar esta exhortación de cambio hacia el objetivo globalmente prescrito. Sin duda, un rasgo distintivo, diferencial de la actitud del Gobierno al declarar la emergencia sanitaria, es que se optó por no ejercer el máximo y explícito poder coercitivo, y para tal fin no se usaron términos como "ordenar" o "prohibir". Lo imperativo fue el mandato de cierre de gran parte del sistema de bienes y servicios de la sociedad uruguaya; así, de modo fáctico o indicial en lugar de simbólico, se controló el comportamiento de la población desde el 13 de marzo.

En estas conferencias gubernamentales, entonces, se ha presentado como objetivo de la manipulación discursiva la transformación de la realidad social en dos etapas: un primer momento declarado de "emergencia sanitaria", en el que se dispuso el cierre de fronteras, la suspensión de vuelos, la cuarentena obligatoria a las personas provenientes de países declarados de riesgo, la prohibición del descenso de cruceros, la suspensión de espectáculos públicos y de las clases presenciales en todos los niveles de enseñanza pública y privada, así como la exhortación al aislamiento social y al cierre preventivo, obligatorio y provisorio de locales comerciales de gran porte. $Y$ un segundo momento que se orientó a instalar como atmósfera o clima de la vida cotidiana de todos los habitantes del país la denominada "nueva normalidad", la cual ha sido impulsada a nivel internacional por la OMS y fue adoptada de modo acrítico, automático, por el Gobierno uruguayo con el respaldo del comité honorario científico local, cuyo acrónimo, $\mathrm{GACH},{ }^{14}$ se ha vuelto un término popular por la amplísima difusión mediática que ha tenido este nuevo organismo.

Esta transformación de la realidad social en dos etapas es un proceso que no excluye la posibilidad de "retrocesos" en la planificación. En este sentido, fue usada por el presidente la imagen de operar desde el Gobierno la ejecución de "tres perillas": una "perilla de sanidad", una "perilla social" y una "perilla económica", a partir de las cuales se puede avanzar o retroceder en estas etapas. Podría decirse que esta oscilación instaurada como esencial para la salvación colectiva está en el núcleo de la nada normal "nueva normalidad". Apenas el Gobierno enunció esa imagen, los informativos televisivos la adoptaron con orgullo, que se tradujo en innumerables reiteraciones teñidas de admiración por lo que percibieron como acertado de esa propuesta retórica.

Estas imaginarias perillas de naturaleza metafórica y narrativa son esenciales para el relato que desarrolla la combinada voz política y mediática. Sin excepción, todos los informativos se alinearon para evocar una y otra vez una analogía deportiva formu-

${ }_{14}$ Grupo Asesor Científico Honorario. 


\section{Austral Comunicación \\ Volumen 10, número 1 (junio de 2021): 87-118 ISSN (I) 2313-9129. ISSN (E) 2313-9137}

lada por uno de los tres líderes del GACH. En mayo, el doctor Rafael Radi ${ }^{15}$ ilustró el letal riesgo que vivía la población a causa de la amenaza del virus SARS-CoV-2 con una metáfora futbolística, la pasión deportiva uruguaya: estaríamos todos en una situación similar a la de la selección uruguaya jugando frente a la de Bolivia en La Paz, a 4000 metros de altura, con un resultado 0 a 0 , pero que, en cualquier momento, lo conquistado con un descomunal esfuerzo colectivo podría cambiar de modo dramático y adverso. La naturaleza de ese duelo en las condiciones más hostiles posibles no solo es comprensible por la mayoría de uruguayos, sino que la visión de "la celeste" ${ }^{16}$ sufriendo una amarga -aun si previsible- derrota es una experiencia disfórica y concitadora de la unanimidad. El manejo retórico del equipo científico está en total consonancia con el utilizado por el Gobierno nacional: mover perillas para controlar cuidadosamente los movimientos de la población tiene admirable sinergia con la estrategia metafórica de colocar ante su imaginación la visión de un escenario futbolístico de respiración dificultosa seguida por una casi inevitable derrota futbolística y épica.

Para un observador externo sería fácil llegar a la conclusión de que las medidas sanitarias adoptadas en Uruguay son extremadamente moderadas si se las compara, por ejemplo, con las empleadas por uno de sus vecinos geográficos: Argentina. Allí, la cuarentena obligatoria y prolongada fue decretada por el Gobierno sin exhortación alguna y con medidas punitivas severas. Precisamente, ese es uno de los alcances de la teoría del imaginario social: el pensamiento de Castoriadis (2013), junto con el modelo semiótico de Peirce, explican cómo cada grupo humano habita en un mundo de la vida determinado; de todos los posibles, el elegido colectivamente corresponde al "imaginario efectivo", el que sostiene instituciones como la política o la científica. Seguir el camino moderado o "amortiguado" (Real de Azúa, 1984) de no ordenar el encierro o aislamiento de los ciudadanos se adecua admirablemente al "peculiar sabor o color de la mediación, la Mentalidad" (Peirce, 1931-1958, 1.533). El efecto paralizante del miedo difundido por los informativos televisivos enmarca las comunicaciones políticas amortiguadas que respetan ese imaginario efectivo o mentalidad. Como resultado de esa fuerte tensión entre la visión sensacionalista del agente de la COVID-19 y la palabra política moderada, surge un acatamiento tan grande como el observado en la nación vecina.

Lo que explica estos senderos gubernamentales y mediáticos que se bifurcan es el "imaginario radical" (Castoriadis, 2013), es decir, la forma innovadora que permite la introducción de nuevos símbolos. Desde el enfoque semiótico, se trata del posibilismo

\footnotetext{
${ }^{15}$ El Dr. Rafael Radi es profesor titular del Departamento de Bioquímica de la Facultad de Medicina de la Universidad de la República y director del Centro de Investigaciones Biomédicas de esa misma casa de estudios (fuente: Facultad de Medicina, Universidad de la República, http://www.bioquimica.fmed.edu.uy/Integrantes\%20English\%20G5. html).

${ }_{16}$ Nombre pasional con el que se habla de ese grupo de futbolistas profesionales.
} 
Fernando Andacht, Gastón Amen

Signos televisivos informativos de un prolongado estado de alarma: el caso uruguayo en los primeros ocho meses de la declaración de emergencia sanitaria

icónico, la forma más básica de la experiencia, lo cualitativo absoluto, porque mediante "la observación directa del ícono" es posible "descubrir otras verdades de su objeto", según Peirce (1931-1958, 2.279). El imaginario radical y la mentalidad o dimensión cualitativa/icónica de la mediación sígnica brindan acceso a los signos con los que metabolizar la realidad que se instaló como "emergencia sanitaria" en el primer trimestre de 2020. En conclusión, el contraste con la tan mentada "grieta" de la sociedad argentina podría no ser tal, y lo que se vive desde el inicio de esta crisis por la conjunción político-mediática puede describirse como una "grieta amortiguada" y, como tal, innegablemente uruguaya. ${ }^{17}$

\section{Las conferencias gubernamentales anuncian una nueva era}

Las ceremonias, de acuerdo con Dayan y Katz (1995), tienen el poder "para dar a luz e infundir significado a nuevas realidades históricas. Es un proceso de reemplazo, dentro del marco ceremonial, de un paradigma dado por otro nuevo y una presentación del nuevo paradigma al mundo" (pp. 130-131). De esto se trataría, a nivel local, en el caso de las conferencias gubernamentales cuando el presidente Lacalle Pou señala repetidamente que hay que adaptarse a la "nueva normalidad", una idea disimuladora de un nuevo orden social que se impone, de carácter tan coercitivo como la obligación de ponerse la máscara o "tapabocas", como se la llama en Uruguay, para poder circular en el transporte público. El llamado "protocolo" no forma parte de lo exhortado, sino que se lo ordena y acompaña con una sanción en caso de su no cumplimiento.

En los "acontecimientos mediáticos transformativos" se proclama una nueva era: "Una ceremonia transformativa es, pues, un punto de inflexión; organiza el tiempo retrospectivamente hasta el momento ceremonial, y prospectivamente desde la ceremonia en adelante" (Dayan y Katz, 1995, p. 131). Esto se puede reconocer en la conferencia de prensa del 17 de abril, en la que Lacalle Pou señala:

Haciendo un poco de historia reciente [...] acerca de las medidas que estamos implementando en estos días, y tratamos de ver un poco qué se hizo en este mes y algunos días desde el 13 de marzo, porque las medidas que hoy estamos tratando de aplicar son consecuencia directa de las medidas que se aplicaron apenas conocidos los primeros casos. Y sobre todo del ejercicio de la libertad responsable que hizo la gran mayoría de uruguayos.

En esta intervención vemos cómo se organiza el tiempo retrospectivamente desde el 13 de marzo hasta el momento de la ceremonia, y luego, prospectivamente, desde el presente ceremonial hacia una nueva situación a la que se apunta, lo que implica, en palabras del presidente, el pasaje "de un aislamiento de alto impacto, a un distanciamiento

\footnotetext{
${ }_{17}$ El número 13 de la revista eXtramuros. La escritura ante el declive del debate público, de noviembre de 2020, está dedicado a reflexionar sobre el alcance del concepto "grieta" en relación con la pandemia y con la gestión política (https://extramurosrevista.org/category/13/).
} 


\section{Austral Comunicación \\ Volumen 10, número 1 (junio de 2021): 87-118 ISSN (I) 2313-9129. ISSN (E) 2313-9137}

social que debe ser sostenido". Esa medida puede ocurrir, con lo cual agrega: "Porque los uruguayos demostraron que hicieron un buen uso de la libertad, con solidaridad y con generosidad". Nuevamente, observamos el uso de un recurso retórico clásico, la captatio benevolentiae, el esfuerzo por seducir al destinatario mediante elogios; se destaca sus virtudes, se le dice que es admirable y eso genera admiración recíproca por quien manifiesta esa encendida admiración. En definitiva, la liminalidad y ceremonialidad que detiene el tiempo crónico en las conferencias gubernamentales apunta a instalar un kairos negativo, no la entrada a un momento glorioso, una conquista, sino el aceptar estas restricciones a la libertad sin que haya suficiente evidencia que las justifique, al tiempo que se reconstruye el pasado y se reorganiza la memoria colectiva.

La nueva era proclamada en esta conferencia gubernamental del 17 de abril, como se dijo, no es otra que la era de "la nueva normalidad", que Lacalle Pou invocó como una idea importada que llegó ya pronta desde el exterior. Se trata de una curiosa renuncia a la autoría y, en buena medida, a la autoridad, ya que la situación sanitaria nacional tuvo, desde el comienzo, características propias, notablemente distintas a las de otras naciones. Así, en esa conferencia, el presidente señaló:

Acuñaron el otro día un término que nos vamos a tener que acostumbrar a usar, que ya no es "el día después", sino la "nueva normalidad". Gente que sabe de estos temas nos corrigió ese concepto y bienvenido sea, el mundo ya no va a ser el mismo, y sin perjuicio de ser grandilocuente, en estos tiempos que vienen va a haber una "nueva normalidad".

Esa actitud celebratoria requiere una ceremonia de proclamación, como si el Poder Ejecutivo hablase sobre una victoria extraordinaria, como la de haber ganado la copa del mundo de fútbol nuevamente, o acordado algo tan trascendente como el tratado del Mercosur en 1991.

El camino discursivo elegido representa la adopción de esa frase o eslogan como la consecuencia natural de aceptar algo que proviene de un lugar donde hay más autoridad. Se trata de apelar a uno de los métodos para llegar a una creencia, el que Peirce (1931-1958, 5.380, 1877) denomina "de autoridad", pues está basado en una persona o institución que posee un saber o poder mayor que el del propio presidente. Esa actitud conlleva un tipo de reconocimiento que puede verse como el anticipo de la coordinación con la comisión de asesores científicos. Así se ha determinado, establecido y normatizado oficialmente algo que a todas luces parece anómalo, anormal y que no merece ni podría aceptar la descripción de "la nueva normalidad". Lo que se limitó a hacer el presidente ese día es, literalmente, "darle la bienvenida" no a la frase, sino -de acuerdo con la máxima pragmática peirceana (Peirce, 1931-1958, 5.3)- a la serie considerable de consecuencias concretas y reales que constituyen el significado cabal de ese concepto complejo que viene a alterar de modo visible e innegable la vida cotidiana de toda una nación. Lo único indiscutible que surge a partir de la enunciación de ese discurso del 17 
Fernando Andacht, Gastón Amen

Signos televisivos informativos de un prolongado estado de alarma: el caso uruguayo en los primeros ocho meses de la declaración de emergencia sanitaria

de abril de 2020 es que el mundo ya no será el mismo. En tal sentido, podemos postular en su intervención la presencia de un verbo performativo (Austin 1962; Searle, 1969), pues el acto mismo de decirlo supone llevar adelante lo dicho, ponerlo en práctica por el hecho de enunciarlo. Ese aspecto cobra una singular importancia, ya que el estado de cosas subsiguiente no depende solo ni mayormente de evidencias de tipo sanitario, sino del uso recurrente de la frase a la que se le dio así carta de ciudadanía en el Uruguay de la crisis sanitaria instaurada el 13 de marzo de 2020.

Dayan y Katz (1995) señalan que "el acontecimiento ceremonial, al introducir un nuevo paradigma, induce a una percepción reflexiva de lo que hubo antes de él. El pasado inmediato queda súbitamente objetivado como una era o un período y recibe un nombre" (p. 134). En este caso, al tiempo anterior al comienzo de la pandemia declarada a nivel mundial y de la emergencia sanitaria a nivel local se lo denominaría ahora "vieja normalidad", cuando lo justo sería hablar de "normalidad" simplemente, pues, como afirmamos antes, es una noción que no admite tal adjetivación y el describirla como "nueva" o "vieja" altera su significación por completo.

\section{La instalación de una nueva geografía simbólica}

Además de organizar de una manera novedosa el tiempo, los "acontecimientos mediáticos transformadores" "afectan también el sentido del lugar de una sociedad [...] Los acontecimientos transformativos mediáticos afectan la geografía simbólica" (Dayan y Katz, 1995, p. 134). Quizás lo más destacable aquí sea el cierre parcial de fronteras, anunciado por el Gobierno ya el 13 de marzo, conjuntamente con la prohibición del descenso de los pasajeros de los cruceros. A esto se le agregó el anuncio, en la conferencia del 15 de marzo, de la suspensión de los vuelos provenientes de Europa a partir del viernes 20 de marzo. En la conferencia del 16 de marzo, Lacalle Pou también señaló que el Gobierno uruguayo había decidido el cierre total de fronteras con Argentina a nivel terrestre, fluvial y aéreo a partir del martes 17 de marzo (quedando exceptuados los ciudadanos uruguayos y residentes en Uruguay y el transporte de mercadería).

Este tipo de medidas diseñó una nueva geografía simbólica, en la que se comenzó a ver a los extranjeros como potenciales vectores del virus, al tiempo que se alentaba a un aislamiento nacional del que no se excluía, en ocasiones, a los ciudadanos uruguayos que, de viaje en el exterior, no conseguían retornar al país, quienes a fin de cuentas también integraban esta "comunidad imaginada" (Anderson, 2016). Es en esta línea que se enmarcaron las iniciativas para repatriar a los uruguayos que se encontraban en otros países, pero que pretendían retornar. Una primera expresión de esta iniciativa en las conferencias gubernamentales ocurrió el 18 de marzo, cuando el entonces canciller Ernesto Talvi anunció que el Gobierno había decidido despachar dos vuelos: uno de la empresa Amaszonas, que saldría en misión como avión del Estado uruguayo y orga- 


\section{Austral Cmunicación \\ Volumen 10, número 1 (junio de 2021): 87-118 ISSN (I) 2313-9129. ISSN (E) 2313-9137}

nizaría el retorno de 90 personas que estaban en la ciudad de Cusco, Perú, y otro de la Fuerza Aérea Uruguaya, que trasladaría desde Lima a otros 34 ciudadanos. El ministro explicó que desde la Cancillería se trabajaba para asegurar el regreso de los uruguayos que se encontraban varados en el exterior.

A través de todas estas medidas de cierre físico y simbólico de fronteras dispuesto por las autoridades, se ha dado un reforzamiento de la "comunidad imaginada" uruguaya. Lo cual, por otra parte, no se puede desligar de ciertos procesos negativos que se han dado paralelamente, como ha sido el surgimiento, ya identificado y denunciado incluso por las Naciones Unidas, de actitudes racistas y xenófobas en Uruguay (Las Naciones Unidas afirma que..., 2020).

\section{El crucero Greg Mortimer}

También en este contexto de cierre de fronteras es que tuvo lugar el muy publicitado desembarco y retorno a sus respectivos países de los pasajeros del crucero Greg Mortimer. En este caso, se pudo reconocer incluso el renacer de una narrativa del Uruguay como país de acogida de perseguidos y carenciados, más allá de que se tratara en este caso de una recepción transitoria de pasajeros de un lujoso crucero, con la finalidad de que, a través del denominado "corredor humanitario", ellos pudieran retornar a sus países de residencia. La decisión de repatriar compatriotas varados en diversos puntos del planeta tomada por ese alto funcionario del Poder Ejecutivo también constituye un caso de lo que se conoce en comunicación política, particularmente, aunque no de modo exclusivo en su fase electoral, como una photo op, es decir, una ocasión ideal para promover a un candidato $\mathrm{o}$ a un político electo en un ambiente o escenario que, desde el punto de vista narrativo-actoral, le resulta ideal, idílico, porque pone de manifiesto y amplifica mediáticamente del modo más favorable y fotogénico posible alguna virtud del actor político. En el caso uruguayo, se trató de una muy prolongada photo op, que duró hasta que el último pasajero y/o tripulante del Greg Mortimer dejó el país o las aguas territoriales.

\section{Un desafío a futuro}

Ya en el cierre del artículo, podemos sugerir una vía más de investigación sobre las conferencias gubernamentales: el análisis del encuadre goffmaniano (Goffman, 1974). Desde ese encuadre teórico, lo que han tratado de hacer las elites gobernantes con la invalorable cooperación unánime y tenaz de los informativos televisivos ha sido resignificar la situación comunicacional mediante una operación de "puesta en clave" (keying) del encuadre primario conversacional o dialógico. Así, la acción semiótica del poder más visible en democracia, el de la presidencia junto a sus varios ministros, 
Fernando Andacht, Gastón Amen

Signos televisivos informativos de un prolongado estado de alarma: el caso uruguayo en los primeros ocho meses de la declaración de emergencia sanitaria

transformó la inusual y ceremonial "transmisión en cadena televisiva", algo que ocurre en contadas y excepcionales circunstancias, en una práctica cotidiana que describimos aquí como un extrañamente prolongado "acontecimiento mediático" de nivel nacional. La más potente justificación y explicación de la eficacia de ese reencuadre situacional es que esas intervenciones político-mediáticas y sanitarias se enmarcan, a su vez, en una situación mucho más amplia, global, que ameritaría tratarse en profundidad en otro artículo, en el que podríamos incorporar otra noción teórica relevante de los estudios de comunicación, como lo es la teoría del "caso conmocionante", tal como la postuló Fernández Pedemonte (2010), ${ }^{18}$ y que si hubiera que resumirlo en una frase, esta podría ser: entramos en una crisis sin término.

\section{Algunas conclusiones sobre signos informativos y alarmantes en la pandemia}

En este trabajo hemos analizado el despliegue de signos informativos en la televisión uruguaya en torno a la "emergencia sanitaria" declarada el 13 de marzo de 2020, que revigorizó los noticieros y representó sin pausa la confluencia de la voz gubernativa y la mediática, propiciando un prolongado estado de alarma. De este modo, pudimos constatar la presencia casi excluyente y desde una sola perspectiva de la temática de la COVID-19. Observamos la presencia prolongada y permanente de signos dedicados a anunciar el desastre inminente, alternados esporádicamente con ciertos sucesos representados mediante una modalidad narrativa épica, con foco en aspectos subjetivos e individuales, como lo fue la "saga" del crucero Greg Mortimer.

Asimismo, dentro de la excepcionalidad de la situación informativa, hemos puesto de relieve la presencia muy frecuente de conferencias gubernamentales, lo que hemos designado como cadenas televisivas de facto, las cuales abordamos a través de los aportes conceptuales de Dayan y Katz (1995) en torno a los "acontecimientos mediáticos", más allá de que no se ajusten completamente a esa teorización. En este sentido, reconocimos que sí comparten con aquellos su carácter de transmisión en directo y remota, así como su naturaleza planificada. Por otro lado, en cuanto a la interrupción de las rutinas, también pudimos constatar que si bien en un principio lo hicieron, luego, con el transcurso de los días, se integraron con fluidez a la estructura informativa diaria y/o semanal, y dejaron de tener ese carácter de excepcionalidad que singulariza a los "acontecimientos mediáticos".

Estas conferencias, entendidas como una variante heterodoxa de las "ceremonias mediáticas transformativas" (Dayan y Katz, 1995), apelaron a mitos relevantes del "imaginario social" (Castoriadis, 2013) uruguayo como una forma tanto de reforzar

\footnotetext{
${ }_{18}$ Para una aplicación de esta perspectiva teórica al estudio de un caso mediático uruguayo, acontecido hace 8 años y ampliamente cubierto por los informativos televisivos, ver Amen (2019).
} 


\section{Austral@municación \\ Volumen 10, número 1 (junio de 2021): 87-118 ISSN (I) 2313-9129. ISSN (E) 2313-9137}

los valores establecidos, contribuir a la integración social y buscar legitimar a las autoridades vigentes como también de asimilar los nuevos e inciertos sucesos vinculados a la declarada pandemia mundial de SARS-CoV-2 y a sus posibles efectos locales en los confines del "imaginario social" uruguayo. En esta línea, destacamos cómo la manipulación discursiva de las conferencias gubernamentales, que asumió en forma acrítica las directrices globales emitidas por la OMS, ha apuntado a cumplir una función transformadora en dos etapas, valiéndose para esto de la imagen verbal de operar desde el Gobierno la ejecución de "perillas", a partir de las cuales se puede avanzar o retroceder en ellas. Esta oscilación estaría en el núcleo de la nada normal "nueva normalidad", idea disimuladora de un nuevo orden social, el cual se nos exige acatar.

\section{Referencias}

Álvarez, L.(1988). Los héroes de las siete y media. Los noticieros en la televisión uruguaya. Claeh.

Amen, G. (2019). Informativos y cárceles: un estudio de la cobertura de los informativos centrales de la televisión abierta uruguaya de la «crisis carcelaria» del 2012. Ediciones Universitarias.

Andacht, F. (1992). Signos reales del Uruguay imaginario. Ediciones Trilce.

Andacht, F. (1996). Paisaje de Pasiones. Pequeño Tratado sobre las Pasiones en Mesocracia. Fin de Siglo.

Andacht, F. (2020a). El nada discreto (des)encanto de la unanimidad en tiempos poco disidentes. eXtramuros. La escritura ante el declive del debate público, (2). https:// extramurosrevista.org/el-nada-discreto-desencanto-de-la-unanimidad/.

Andacht, F. (2020b). La agridulce y muy ancha grieta del kitsch pandémico. eXtramuros. La escritura ante el declive del debate público, (11). https://extramurosrevista.org/ la-agridulce-y-muy-ancha-grieta-del-kitsch-pandemico/.

Anderson, B. ([1983] 2016). Comunidades imaginadas. Reflexiones sobre el origen y la difusión del nacionalismo. Fondo de Cultura Económica.

Austin, J. L. (1962). How to Do Things with Words (Eds. J. O. Urmson y M. Sbisà). Clarendon Press.

Bayce, R. ([2003] 2005). Cultura, identidades, subjetividades y estereotipos: Preguntas generales y apuntes específicos en el caso del fútbol uruguayo. En Alabarces, P. (Comp.), Futbologías. Fútbol, Identidad y Violencia en América Latina. CLACSO/ Libronauta Argentina.

Borges, L. (2019). La historia escondida del Uruguay. Mitos, verdades y dudas de nuestra historia. Ediciones B.

Canguilhem, G. (1991). The normal and the pathological. Zone Books.

Carlón, M. (2009). ¿Autopsia a la televisión? Dispositivo y lenguaje en el fin de una era. 
En Carlón, M.y Scolari, C. A., El fin de los medios masivos. El comienzo de un debate (pp. 159-187). La Crujía.

Carlón, M. y Scolari, C. A. (2009). El fin de los medios masivos. El comienzo de un debate. La Crujía.

Castoriadis, C. ([1975] 2013). La institución imaginaria de la sociedad. Tusquets Editores.

Dayan, D. y Katz, E. (1995/1992). La historia en directo. La retransmisión televisiva de los acontecimientos. Ediciones G. Gili.

Fernández Pedemonte, D. (2010). Conmoción pública. Los casos mediáticos y sus públicos. La Crujía.

Focás, B. (30 de marzo de 2020). Las noticias en tiempos de cuarentena ¿Cuánta información somos capaces de soportar? Página/12. https://www.pagina12.com. ar/256408-cuanta-informacion-somos-capaces-de-soportar?fbclid=IwAR0gG-p7 44I9aGcU9PqyNFGufjd8pJRylvhijvYPtcNlBasgd6ZdPtlFwBc.

Foucault, M. ([1976] 1978). Historia de la sexualidad 1- La voluntad de saber. Siglo XXI.

Foucault, M. ([1997] 2000). Defender la sociedad. Curso en el Collège de France (19751976). Fondo de Cultura Económica.

Freud, S. (1919). The 'Uncanny'. En The Standard Edition of the Complete Psychological Works of Sigmund Freud, Volume XVII (1917-1919): An Infantile Neurosis and Other Works (pp. 217-256). Strachey \& Freud.

Gilder, G. (1992). Life After Televisión. The Coming Transformation of Media and American Life. Norton.

Goffman, E. (1974). Frame analysis: An essay on the organization of experience. Harvard University Press.

Goffman,E.([1959] 1997).Lapresentación de la persona en la vida cotidiana.Amorrortu.

Gómez González, B. y Escobar, A. (2006). Estrés y sistema inmune. Revista Mexicana de Neurociencia, 7(1), 30-38.

Kermode, F. (1967). The sense of and ending. Oxford University Press.

Las Naciones Unidas afirma que el Covid-19 generó expresiones de racismo y xenofobiaque "antes no se veían" en Uruguay. (20 al 26 de agosto de 2020). Búsqueda. https://www. busqueda.com.uy/Secciones/Las-Naciones-Unidas-afirma-que-el-Covid-19genero-expresiones-de-racismo-y-xenofobia-que-antes-no-se-veian-en-Uruguayuc1106?fbclid=IwAR2Kg55FaIiCQOpZDP3TM6Ug-68JGt4I2b87zhWadB8c3QwbVQFKSJYvHo.

Medina, F. (18 de abril de 2020). La televisión uruguaya aumenta su rating mientras se adapta a la cuarentena. La Diaria. https://ladiaria.com.uy/articulo/2020/4/ la-television-uruguaya-aumenta-su-rating-mientras-se-adapta-a-la-cuarentena/.

Natalevich, M. y Silvera, L. (2011). Disparando noticias. Estudio sobre el tratamiento 


\section{Austral Cmunicación \\ Volumen 10, número 1 (junio de 2021): 87-118 ISSN (I) 2313-9129. ISSN (E) 2313-9137}

informativo de la crónica policial televisiva en Uruguay (Memoria de grado). Departamento de Comunicación, Facultad de Ciencias Humanas, Universidad Católica del Uruguay.

No Toquen Nada. (2 de noviembre de 2020). Lucía Alonso en No Toquen Nada [Archivo de video]. Facebook. https://www.facebook.com/watch/?v=834724420664098.

Origin of 'the new normal' as a freestanding phrase. (14 de diciembre de 2014). English Language \& Usage. https://english.stackexchange.com/questions/215012/ origin-of-the-new-normal-as-a-freestanding-phrase.

Para el $44 \%$ de los uruguayos hoy el principal problema del país es la salud. (21 de abril de 2020). Telemundo. https://www.teledoce.com/telemundo/nacionales/ para-el-44-de-los-uruguayos-hoy-el-principal-problema-del-pais-es-la-salud/.

Peirce, C. S. (1931-1958). Collected papers of Charles Sanders Peirce (Ed. C. Hartshorne, P. Weiss y A. Burks, Vol. I-V). Harvard University Press.

Pereira, A. (2014). Los informativos de los ochenta: cambios y ¿evolución? En Delgado, L. (Ed.), Cuaderno de Historia No 13. Cultura y comunicación en los ochenta (pp. 166-185). Biblioteca Nacional.

Pérez de Silva, J. (2000). La televisión ha muerto. La nueva producción audiovisual en la era de Internet: la tercera revolución industrial. Gedisa.

Perroni, E. (2009). Análisis de comunicación de temáticas de seguridad ciudadana en noticieros de tv. Ministerio de Desarrollo Social, Gobierno de Uruguay.

http://archivo.mides.gub.uy/3338/analisis-de-comunicacion-\%20 de-tematicas-de-seguridad-ciudadana-en-noticieros-de-tv

Piscitelli, A. (1995). Paleo, neo y post-televisión. Del contrato pedagógico a la interactividad generalizada. En Gómez Mont, C. (Ed.), La metamorfosis de la TV (pp. 11-30). Universidad Iberoamericana.

Piscitelli, A. (1998). Post-televisión. Ecología de los medios en la era de Internet. Paidós.

Radakovich, R. (2009). Década de la transición digital en Uruguay. En Dominzaín, S., Rapetti, S. y Radakovich, R., Imaginarios y consumo cultural, Segundo Informe Nacional sobre Consumo y Comportamiento cultural, Uruguay 2009 (pp. 107-129). Observatorio Universitario de Políticas Culturales.

Real de Azúa, C. (1964). El impulso y su freno. Tres décadas de batllismo. Ediciones de la Banda Oriental.

Real de Azúa, C. (1984). Uruguay, ¿una sociedad amortiguadora? CIESU/Ediciones de la Banda Oriental.

Rial, J. (1986). El "imaginario social" uruguayo y la dictadura. Los mitos políticos (dere) construcción. En Perelli, C. y Rial, J., De mitos y memorias políticas. La represión, el miedo y después... (pp. 15-37). Ediciones de la Banda Oriental.

Scolari, C. (2009). This is the end. Las interminables discusiones sobre el fin de la 
televisión. En Carlón, M. y Scolari, C. A., El fin de los medios masivos (pp. 189-208). El comienzo de un debate. La Crujía.

Searle, J. R. (1969). Speech Acts. An Essay in the Philosophy of Language. Cambridge University Press.

Tabárez, N. (19 de marzo de 2020). En tiempos de coronavirus los noticieros llegan a altísimas cifras de rating. El Observador. https://www.elobservador.com.uy/ nota/en-tiempos-de-coronavirus-los-noticieros-llegan-a-altisimas-cifras-derating-202031914305.

Toffler, A. ([1980] 1982). La tercera ola. Plaza \& Janes.

Valles, M. (1997). Técnicas cualitativas de investigación social. Reflexión metodológica y práctica profesional. Editorial Síntesis. 